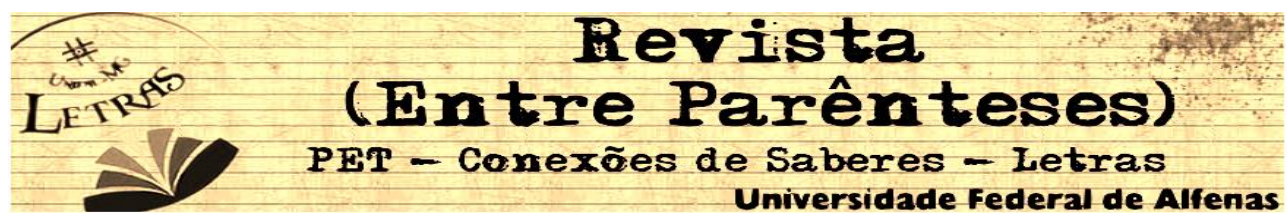

\title{
AS NOVAS TECNOLOGIAS E OS LETRAMENTOS PARA A EDUCAÇÃO DO SÉCULO XXI
}

\author{
Adolfo Tanzi Neto ${ }^{1}$ \\ Universidade Estadual de Campinas (Unicamp) \\ professor.tanzi@gmail.com
}

\begin{abstract}
Resumo: Desde o advento da internet tem se discutido o impacto da tecnologia em nosso trabalho, educação, cultura, identidade, relações pessoais e até mesmo lazer. Em tempos modernos a tecnologia está a nosso favor para muitos usos, que a cada dia se ampliam. Novas tecnologias de informação e de comunicação (TICs) estão sendo constantemente disponibilizadas no mercado, o que nos leva como educador a pensar na formação desses alunos-usuários, mas uma formação que desenvolva a autonomia, o senso crítico e a reflexão, de modo que os usuários não sejam apenas receptores de informações. Esse artigo traz um breve levantamento das questões básicas de alfabetização, alfabetismos, letramentos em nosso país, chegando a uma reflexão maior e iminente que são os multiletramentos na era contemporânea.
\end{abstract}

Palavras-Chave: novas tecnologias; letramentos; multiletramentos.

Abstract: The advent of Internet has caused a great impact in the fields of work, education, culture, identity, personal relations even in our leisure activities. In modern life technology is available for many uses and it is also going through constantly changes. New Information and Communication Technologies (ICTs) are on demand, challenging educators to think about the future education of the ICTs users, but an education that provides autonomy, critical thinking, reflection, in a way that they are not only receptors of information. This article presents a brief survey of the basic questions of literacy and literacies in our country, reaching a broader reflection upon the imminent questions of multiliteracies in the contemporary era.

Key-words: new technologies; literacies; multiliteracies.

\section{Introdução}

Com o desenvolvimento das Tecnologias da Informação e da Comunicação (TICs) ${ }^{2}$ na sociedade, o que nos levou a repensar

\footnotetext{
${ }^{1}$ Mestrando em Linguística Aplicada (Unicamp)

1 Revista (Entre Parênteses) 


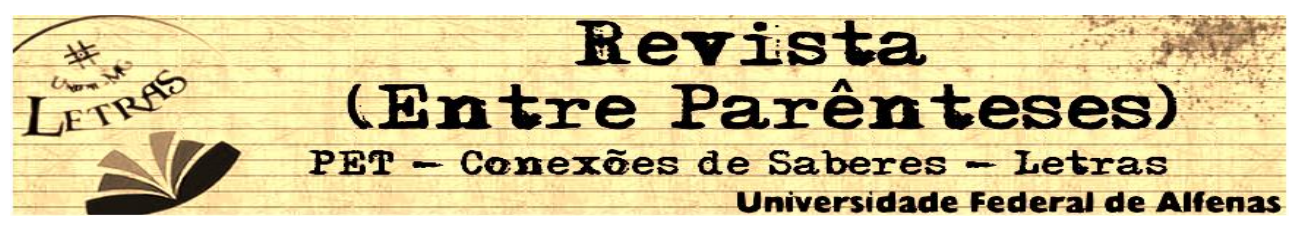

novas formas de organização social, econômica, política e educacional, hoje chamada de Sociedade da Informação - SI (COLL; MONEREO, 2010) -, passamos por profundas transformações nas práticas sociais impostas por esse novo cenário.

Devido a essas transformações, estamos diante de novos paradigmas educacionais trazidos por esse rápido crescimento das TICs em escala mundial. Sendo assim, o grande desafio que se nos coloca é pensarmos a educação do século XXI para essa sociedade da informação, por meio de um ensino que promova desafios que colaborem para a inserção do indivíduo na sociedade contemporânea, que engendre novas formas de viver, trabalhar, relacionar-se, produzir e oferecer serviços.

O impacto da Internet nessa nova geração de jovens os levou a buscar não apenas informações, mas a criar complexos entrelaces globais, sociais e educacionais, contribuindo, portanto, para o aparecimento das "sociedades virtuais".

Shayo et al., (2007) aponta quatro forças ou fatores impulsionadores da rápida expansão das "sociedades virtuais" no mundo moderno: a) o desenvolvimento de economias globais; b) as políticas nacionais de apoio à Internet; c) o crescente letramento digital da população; e d) a melhoria gradual das infraestruturas tecnológicas. A Figura 1 mostra essas forças impulsionadoras nas atividades humanas e nas novas práticas que a elas se associam.

2 Referimo-nos especialmente à tecnologia eletrônica, com destaque para a informática, o computador e a Internet. 


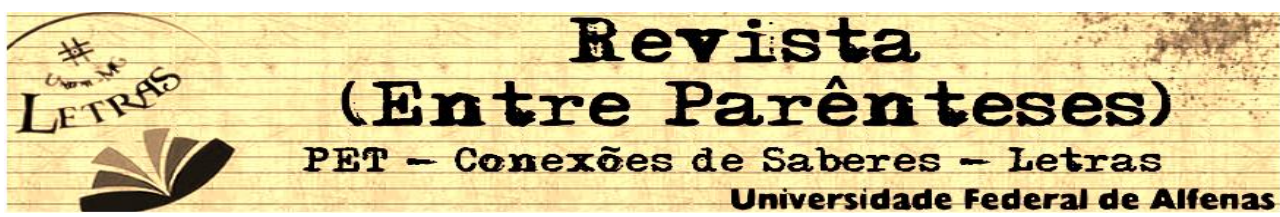

Forças Impulsoras

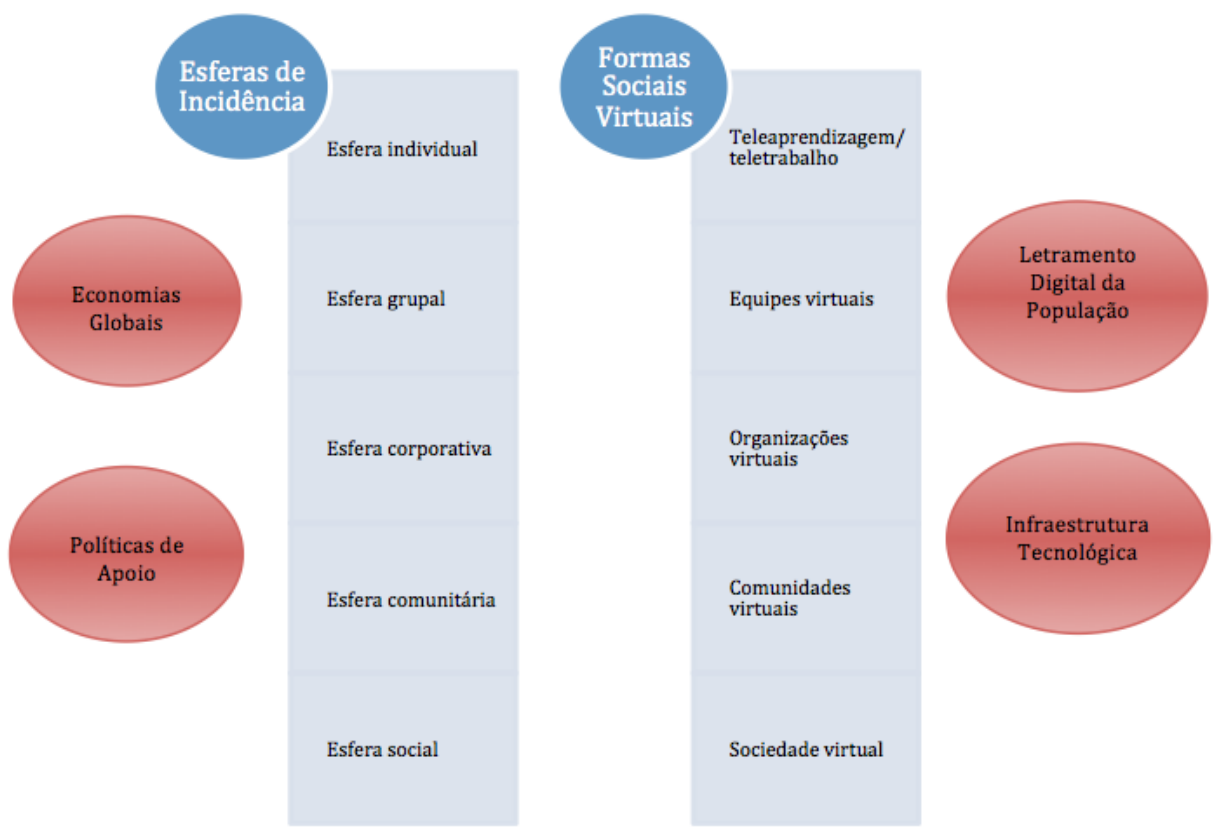

Figura 1: Forças Impulsoras

Fonte: Adaptado de SHAYO, 2007, p.188 apud COLL; MONEREO, 2010, p. 16.

Com a globalização, empresas expandiram seus mercados para diferentes continentes, fazendo o uso das TICs para se inserirem no comércio mundial. As políticas de apoio firmadas entre diferentes países alavancaram o processo de teletrabalho que se firmou no mercado global, trazendo a necessidade de capacitação de pessoal em diferentes partes do mundo e ampliando o mercado de teleaprendizagem.

Países mais desenvolvidos aumentaram seus investimentos em TICs, melhorando suas infraestruturas e redes de comunicação, ajudando seus cidadãos a enfrentarem os desafios do comércio (ebusiness), do trabalho (e-work), da governabilidade (e-governance) e da educação (e-learning) (COLL; MONEREO, 2010, p. 17).

Nesse cenário, podemos observar que, a cada dia, estamos mais inseridos na sociedade virtual, trazendo à população a 


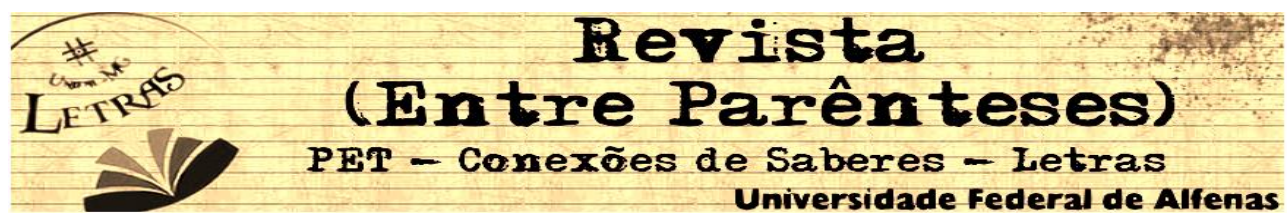

necessidade iminente de novas práticas de letramento que envolvam ferramentas e recursos digitais (novos letramentos).

Parece-nos essencial repensarmos a educação para essas novas práticas de letramento, partindo de uma visão mais ampla, voltada para os "multiletramentos" que estão sempre interconectados às sociedades em que operam e ao papel das pessoas na sociedade em que vivemos.

\section{Alfabetismo no Brasil}

Para darmos início à discussão, partiremos dos dados do INAF $^{3}$ (Indicador de Alfabetismo Funcional) de 2009. INAF mede nacionalmente os diferentes níveis de alfabetismos no Brasil, dados esses usados para avaliar o sistema educacional do país. Para isso, toda a população brasileira das zonas rurais e urbanas é classificada em quatro níveis, de acordo com a Tabela $1^{4}$, em suas habilidades de leitura/escrita (letramento ${ }^{5}$ ) e em matemática (numerando).

${ }^{3} \mathrm{O}$ Inaf - Indicador de Alfabetismo Funcional - Tem o objetivo de oferecer à sociedade informações sobre as habilidades e práticas de leitura, escrita e matemática dos brasileiros entre 15 e 64 anos de idade, de modo a fomentar o debate público, estimular iniciativas da sociedade civil e subsidiar a formulação de políticas nas áreas de educação e cultura.
Retirada
do
site
do Instituto
Montenegro http://www.ipm.org.br/ipmb pagina.php?mpg=4.03.00.00.00\&ver=por acesso em 30/04/2011. O Instituto Paulo Montenegro é uma organização sem fins lucrativos, criada em 2000, com o objetivo de desenvolver ações que contribuam para a melhoria da qualidade do sistema de ensino do país.

${ }^{5} \mathrm{Em}$ breve discutiremos o que tomamos por nossa visão de letramento.

\section{4} Revista (Entre Parênteses) 


\section{Analfabetos funcionais}

Analfabetismo - Corresponde à condição dos que não conseguem realizar tarefas simples que envolvem a leitura de palavras e frases ainda que uma parcela destes consiga ler números familiares (números de telefone, preços etc.).

Alfabetismo rudimentar - Corresponde à capacidade de localizar uma informação explícita em textos curtos e familiares (como um anúncio ou pequena carta), ler e escrever números usuais e realizar operações simples, como manusear dinheiro para o pagamento de pequenas quantias ou fazer medidas de comprimento usando a fita métrica.

\section{Alfabetizados funcionalmente}

Alfabetismo básico - As pessoas classificadas neste nível podem ser consideradas funcionalmente alfabetizadas, pois já leem e compreendem textos de média extensão, localizam informações mesmo que seja necessário realizar pequenas inferências, leem números na casa dos milhões, resolvem problemas envolvendo uma sequência simples de operações e têm noção de proporcionalidade. Mostram, no entanto, limitações quando as operações requeridas envolvem maior número de elementos, etapas ou relações.

Alfabetismo pleno - Classificadas neste nível estão às pessoas cujas habilidades não mais impõem restrições para compreender e interpretar elementos usuais da sociedade letrada: leem textos mais longos, relacionando suas partes, comparam e interpretam informações, distinguem fato de opinião, realizam inferências e sínteses. Quanto à matemática, resolvem problemas que exigem maior planejamento e controle, envolvendo percentuais, proporções e cálculo de área, além de interpretar tabelas de dupla entrada mapas e gráficos.

Tabela 1: Classificação de alfabetismos / Fonte: Instituto Montenegro 


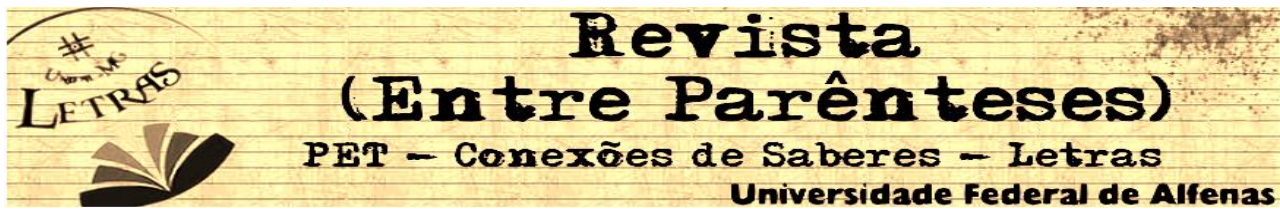

Os dados a seguir foram apresentados pelo INAF 2009 para a população entre 15 e 64 anos em números percentuais.

\begin{tabular}{|c|c|c|c|c|c|c|}
\hline & $\begin{array}{l}2001- \\
2002\end{array}$ & \begin{tabular}{|l}
$2002-$ \\
2003
\end{tabular} & $\begin{array}{l}2003- \\
2004\end{array}$ & $\begin{array}{l}2004- \\
2005\end{array}$ & $\mid 2007$ & 2009 \\
\hline Analfabeto & $\mid 12$ & 13 & 12 & 11 & 9 & 7 \\
\hline Rudimentar & 27 & 26 & 26 & 26 & 25 & 21 \\
\hline Básico & 34 & 36 & 37 & 38 & 38 & 47 \\
\hline Pleno & 26 & 25 & 25 & 26 & 28 & 25 \\
\hline
\end{tabular}

Tabela 2: Evolução do Indicador de Alfabetismo

Fonte: Site Instituto Montenegro ${ }^{6}$

Podemos observar pelos dados por classificação de alfabetismos que houve em 2009 para os brasileiros entre 15 e 64 uma redução percentual nos chamados "analfabetos absolutos" de $9 \%$ para $7 \%$ entre 2007 e 2009. Para o alfabetismo rudimentar houve uma queda ainda mais expressiva de 6\%, o que amplia a quantidade de brasileiros adultos classificados como funcionalmente alfabetizados. O alfabetismo básico apresenta um crescimento contínuo passando de 34\% em 2001-2002 para 47\% em 2009. Infelizmente, para o alfabetismo pleno não mostra crescimento, tendo uma oscilação de um quarto do total dos brasileiros, se enquadrando apenas na margem de erro da pesquisa.

\footnotetext{
${ }^{6}$ http://www.ipm.org.br/ipmb pagina.php?mpg=4.03.00.00.00\&ver=por Acesso em: 30 abr. 2011. 


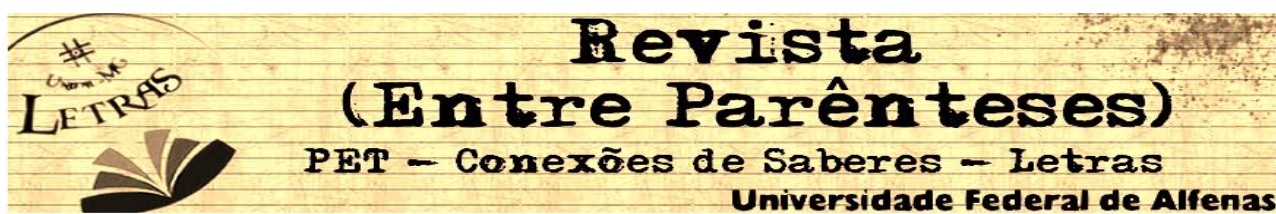

Já a tabela 3 abaixo apresenta os dados levantados segundo - grau de escolaridade da mesma população em números percentuais.

\begin{tabular}{|c|c|c|c|c|c|}
\hline \multicolumn{6}{|c|}{$\begin{array}{l}\text { Nível de Alfabetismo, segundo a escolaridade } \\
\text { População de } 15 \text { a } 64 \text { anos (\%) }\end{array}$} \\
\hline \multicolumn{6}{|c|}{ 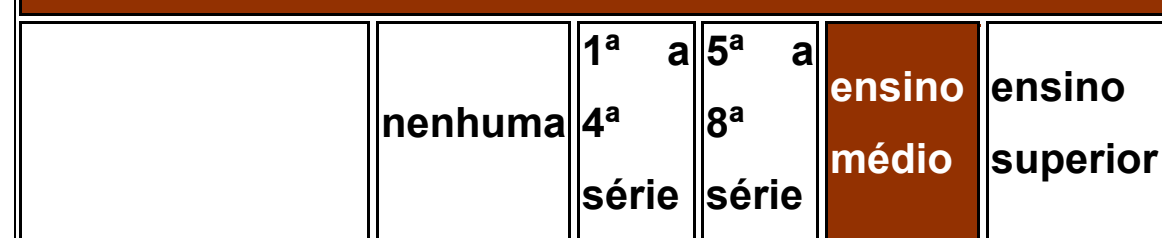 } \\
\hline Analfabeto & 66 & 10 & 0 & 0 & 0 \\
\hline Rudimentar & 29 & 44 & 24 & 6 & 1 \\
\hline Básico & 4 & 41 & 61 & 56 & 31 \\
\hline Pleno & 1 & 6 & 15 & 38 & 68 \\
\hline $\begin{array}{l}\text { Analfabetos } \\
\text { Funcionais }\end{array}$ & 95 & 54 & |24 & 6 & 1 \\
\hline \begin{tabular}{|l|} 
Alfabetizado \\
Funcionalmente
\end{tabular} & 5 & 46 & $\mid 76$ & 94 & 99 \\
\hline
\end{tabular}

Tabela 3: Evolução de Indicador de Alfabetismo

Fonte: Site Instituto Montenegro ${ }^{7}$

Os dados acima mostram que $44 \%$ dos brasileiros que frequentaram as escolas até a $4^{a}$ série atingiram, no máximo, o grau rudimentar de alfabetismo. O que nos é mais alarmante é o fato de que $10 \%$ desses alunos podem ser analfabetos absolutos, mesmo

\footnotetext{
${ }^{7}$ http://www.ipm.org.brlipmb pagina.php?mpg=4.03.00.00.00\&ver=por, Acesso em: 30 abr. 2012. 


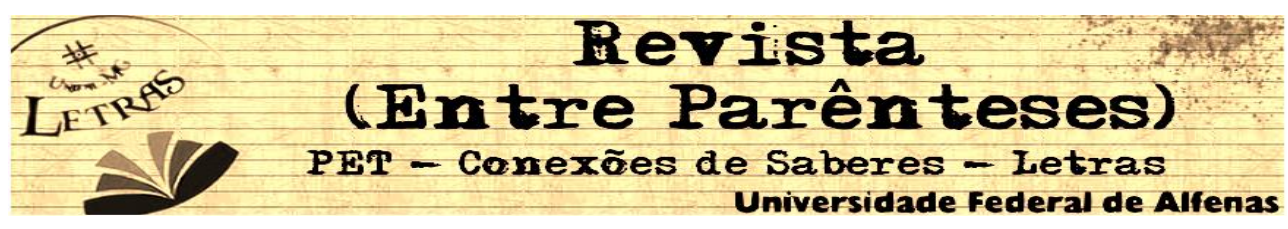

tendo passado 4 anos dentro da escola cursando o ensino fundamental.

Para os que cursaram da $5^{\underline{a}}$ a $8^{\underline{a}}$ séries, os dados mostram que apenas $15 \%$ são considerados plenamente alfabetizados, sendo que $24 \%$ dos alunos que concluíram essa etapa do ensino fundamental permanecem no nível rudimentar. Para os que cursaram alguma série ou completaram o ensino médio, somente $38 \%$ atingiram o nível pleno de alfabetismo, sendo que para esse grupo o esperado seria $100 \%$.

Entre os alunos que chegaram ao ensino superior somente $68 \%$ do grupo têm pleno domínio das habilidades de escrita e das habilidades matemáticas.

Pelos dados apresentados, podemos notar o insucesso ou fracasso escolar da população brasileira no último século. A partir desses dados, pesquisadores da área têm discutido acerca das necessidades eminentes para que esse quadro da educação brasileira mude.

Para Rojo uma das formas de melhoria desse quadro seria "tornar a experiência na escola um percurso significativo em termos de letramentos e de acesso ao conhecimento e à informação" (ROJO, 2009, p. 8). Proposto também seria a questão de alfabetizar letrando.

Para tanto Rojo (2010, p. 3), comenta que:

O que temos nos Brasil hoje é um problema com os letramentos do alunado e não com a sua alfabetização. Não será a alfabetização que poderá dar jeito nisso, mas sim, eventos escolares de letramento que provoquem a inserção do alunado em práticas letradas contemporâneas e, com isso, desenvolvam as competências/capacidades de leitura e escrita requeridas na atualidade (alfabetismos). 


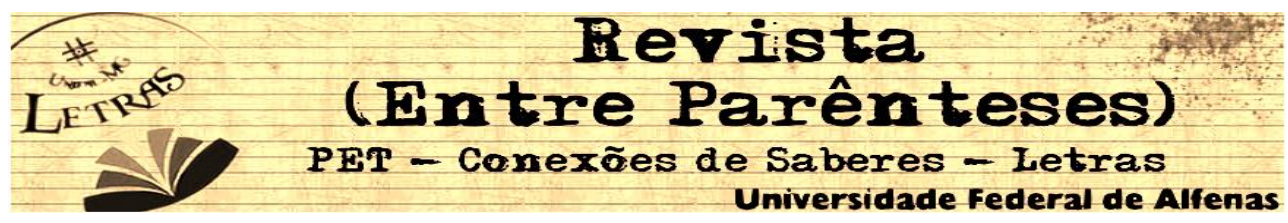

A fim de discutirmos as questões de letramentos, faremos uma breve discussão dos conceitos de alfabetização, alfabetismos e de letramento postulados por alguns pesquisadores do assunto.

\section{Alfabetização, alfabetismos e letramento}

Rojo (2009, p. 10) nos traz a compreensão dos conceitos de alfabetização, alfabetismo e letramento, sendo "um conjunto muito diversificado de práticas sociais situadas que envolvem sistemas de signos, como a escrita ou outras modalidades de linguagem, para gerar sentidos."

A alfabetização parte do princípio de alfabetizar como uma ação de ensinar a ler e a escrever, levando o aprendiz a conhecer do alfabeto a mecânica da escrita e leitura, tornando-se assim nesse processo alfabetizado. (ibidem).

Na perspectiva de Rojo (2009), o alfabetismo é um conceito sócio-historicamente determinado com grande complexidade por envolver as capacidades de leitura e de escrita, e por estas serem capacidades múltiplas e variadas, pois

para ler não basta conhecer o alfabeto e decodificar letras e sons da fala. É preciso compreender o que se lê, isto é, acionar o conhecimento de mundo para relacioná-lo com os temas do texto, inclusive o conhecimento de outros textos/discursos (intertextualizar), prever, hipotetizar, inferir, comparar informações, generalizar. É preciso também interpretar, criticar, dialogar com o texto. (ROJO, 2009, p.10-11)

Para a questão do letramento ${ }^{8}$ Kleiman $(1995$, p. 15) nos traz que, na tentativa de se separar os estudos sobre o impacto social da

8 O termo "letramento" foi usado pela primeira vez por Mary Kato, em 1986 (KLEIMAN, 1995 p.17 apud KATO, 1986, p. 7), advindo da tradução do inglês de literacy.

9 Revista (Entre Parênteses)

ISSN 2238-4502 


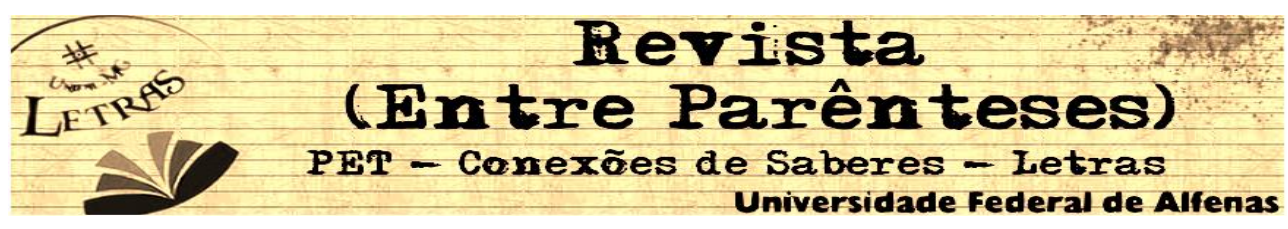

escrita dos estudos sobre alfabetização, o conceito de letramento começou a circular nos meios acadêmicos.

Para Kleiman (1995, p. 16), os estudos sobre letramento "examinam o desenvolvimento social que acompanhou a expansão dos usos da escrita desde o século XVl", incluindo as mudanças políticas, sociais, econômicas e cognitivas relacionadas ao grande uso da escrita nas sociedades tecnológicas. Kleiman (1995, p. 1819) define letramento como "um conjunto de práticas sociais que usam a escrita, como sistema simbólico e como tecnologia, em contextos específicos, para objetivos específicos."

Segundo Rojo (2009, p. 98):

- letramento busca recobrir os usos e práticas sociais de linguagem que envolvem a escrita de uma ou de outra maneira, sejam eles valorizados ou não valorizados, locais ou globais, recobrindo contextos sociais diversos (família, igreja, trabalho, mídias, escola, etc.), numa perspectiva sociológica, antropológica e sociocultural.

Para Street (1993, p. 7), partindo-se de um enfoque ideológico - autor pondera que as práticas de letramento estão "indissoluvelmente ligadas às estruturas culturais e de poder da sociedade" e reconhece que a variedade de práticas culturais está associada à leitura e à escrita em diferentes contextos.

Assim podemos inferir que somente alfabetizar os alunos que estão inseridos em uma Sociedade da Informação não seja suficiente, e que o distanciamento entre as práticas sociais dos alunos e o currículo escolar corrobora para o contínuo fracasso e desinteresse pelas questões relacionadas à vida escolar, e que é preciso que sejam discutidas possibilidades para que esse quadro do insucesso e desmotivação escolar mude. 


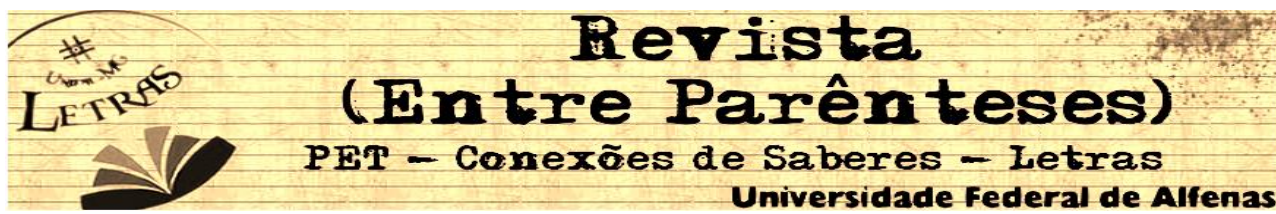

Multiletramentos, grupo de Nova Londres (EUA)

O Grupo de Nova Londres (NEW LONDON GROUP, 1996) ${ }^{9}$ discute sobre o futuro da pedagogia do letramento, trazendo à luz uma pedagogia que deva incluir a multiplicidade de textos e de discursos, com enfoque em dois fatores principais: o primeiro deles é o da diversidade cultural e linguística das sociedades globalizadas, voltada para as culturas multifacetadas que se entrelaçam e para a pluralidade de textos que nelas circulam. $O$ segundo fator refere-se a uma pedagogia que leve em conta o rápido crescimento e a variedade de formatos de textos associados à informação e às tecnologias multimídia, como ter competências para entender diferentes formas representacionais de informação, como as imagens em sua relação com o texto escrito, ou até mesmo o formato de algo no ambiente multimídia. Os autores trazem a proposta de uma educação voltada para as necessidades iminentes do século XXI, ou seja, de uma educação para os (multi)letramentos.

Kalantzis e Cope (2006a) partem do pressuposto de que, como a cada dia as identidades humanas se tornam mais divergentes e suas fronteiras mais tênues, o fato central da língua se torna a multiplicidade de seus significados. Assim, como há múltiplas facetas em nossas identidades, há múltiplos discursos de

\footnotetext{
${ }^{9}$ A discussão sobre o futuro da pedagogia dos multiletramentos é coautorada por: Courtney Cazden, Universidade de Harvard, Faculdade de Educação, EUA; Bill Cope, Instituto de Línguas Nacionais e Letramento da Austrália, Centro de Comunicação e Cultura do Trabalho, Universidade de Tecnologia, Sidnei, e Universidade James Cook do Norte de Queensland, Austrália; Norman Fairclough, Centro para Línguas na Vida Social, Universidade de Lancaster, Reino Unido; Jim Gee, Hiatt Centro de Educação Urbana, Universidade Clark, EUA; Mary Kalantzis, Instituto de Estudos Interdisciplinares, Universidade James Cook do Norte de Queensland, Austrália; Instituto de Educação Gunther Kress, Universidade de Londres, Reino Unido; Allan Luke, Faculdade de Educação, Universidade de Queensland, Austrália; Carmen Luke, Faculdade de Educação, Universidade de Queensland, Austrália; Sarah Michaels, Hiatt Centro de Educação Urbana, Universidade Clark, EUA; Martin Nakata, Escola de Educação, Universidade James Cook do Norte de Queensland, Austrália.
} 


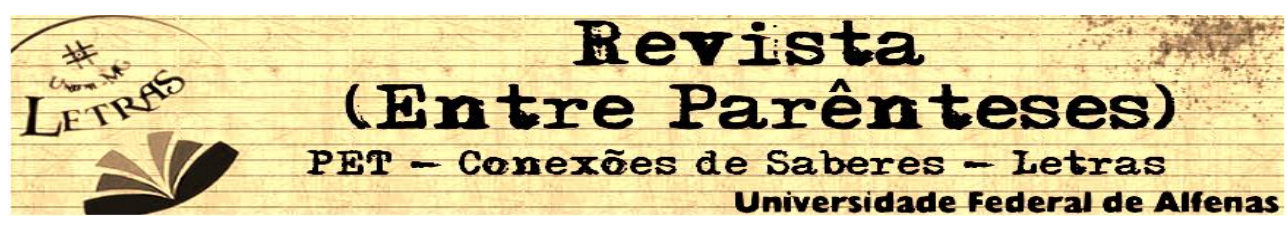

identidades e múltiplos discursos de reconhecimento a serem negociados. Temos que ser proficientes ao negociarmos as identidades que existem em cada um de nós e com tantas outras identidades que nos deparamos no dia a dia em nossas vidas (KALANTZIS; COPE, 2006a, p. 9, tradução nossa).

Essa multiplicidade de significados traz novos desafios para a sala de aula. Na contemporaneidade, a educação adequada deve ser multicultural e contemplar projetos (designs) ${ }^{10}$ de futuro, ou seja, uma proposta pedagógica em que considere três dimensões que tiveram grandes mudanças na contemporaneidade: a da diversidade produtiva (nas questões do trabalho), a do pluralismo cívico (nas questões da cidadania) e a das identidades multifacetadas (nas questões da vida pessoal).

Na dimensão da diversidade produtiva, ou seja, no campo do trabalho, Kalantzis e Cope (2006c) afirmam que a nossa sociedade não se organiza mais à maneira fordista, em que o trabalho era divido em linha de produção e a produção de consumo era em massa. Na era pós-fordista, o trabalhador tem que ser multicapacitado, multitarefa, autônomo e flexível para se adaptar a constantes mudanças.

Rojo (2013, p. 14) enfatiza que:

a logística de negociar diferenças e mudanças leva a organização do trabalho a uma nova fase, a da diversidade produtiva, inclusive em termos de especialização em nichos, de terceirização da produção e da customização do consumo. Para os autores, educar para esta realidade requer uma epistemologia e uma pedagogia do pluralismo: "uma maneira particular de aprender e conhecer o mundo em que a diversidade local e a proximidade global tenham importância crítica".

${ }^{10}$ Tradução de Rojo, 2013, p. 14.

12 Revista (Entre Parênteses) ISSN 2238-4502 


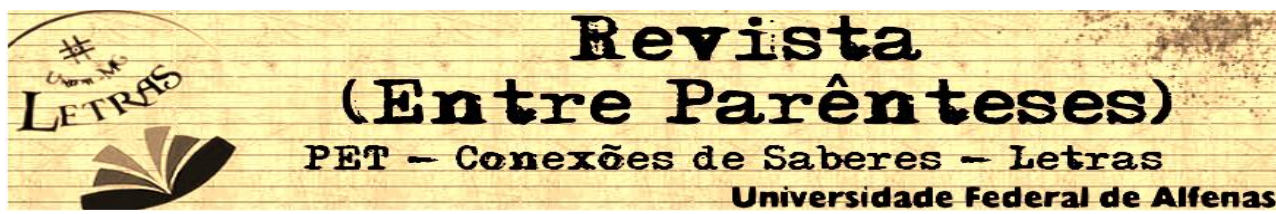

$\mathrm{Na}$ dimensão do pluralismo cívico, isto é, no campo da cidadania, os autores trazem que a escola deve capacitar os alunos para a habilidade de expressarem e de representarem identidades multifacetadas, apropriadas a diferentes modos de vida, espaços cívicos e contextos de trabalho em que cidadãos se encontram. Ainda segundo Rojo (2013, p. 15), deve haver

a ampliação dos repertórios culturais apropriados ao conjunto de contextos onde a diferença tem de ser negociada; [...] "a capacidade de se engajarem numa política colaborativa que combina diferenças em relações de complementaridade".

Na dimensão das identidades multifacetadas, ou seja, na vida pessoal, os autores acreditam que, por vivermos em diferentes culturas híbridas e que a cada dia se tornam mais personalizadas, temos uma consciência descentrada e fragmentada, ou seja, identidades multifacetadas. A escola deve buscar um pluralismo que integre e que caminhe opostamente à fragmentação; a diversidade precisa ser o centro da discussão, buscando novas formas de consciência, constantemente lendo o mundo criticamente para compreender os interesses culturais divergentes que informam significações e ações, suas relações e suas consequências.

Para Kalantzis e Cope (2006b), há quatro conceitos e movimentos pedagógicos relevantes para a pedagogia dos multiletramentos: a prática situada, a instrução aberta, o enquadramento crítico e a prática transformadora. Tais conceitos não devem ser vistos como uma sequência rígida de aprendizado, nem substituir práticas existentes de letramento. O objetivo é trazer ideias ou ângulos de apoio para o que o professor faz, como pode ser observado na Tabela 4 a seguir: 


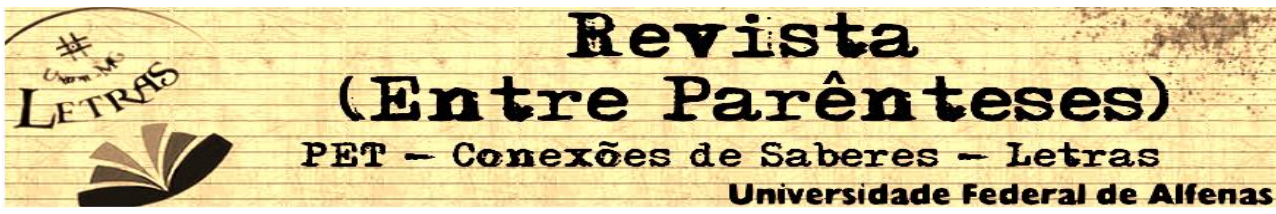

\begin{tabular}{|c|c|c|c|}
\hline $\begin{array}{c}\text { Prática } \\
\text { Situada }\end{array}$ & Instrução Aberta & $\begin{array}{c}\text { Enquadramento } \\
\text { Crítico }\end{array}$ & $\begin{array}{c}\text { Prática } \\
\text { Transformadora }\end{array}$ \\
\hline $\begin{array}{c}\text { práticas de } \\
\text { ensino de } \\
\text { processo, } \\
\text { imersão e } \\
\text { aprendizagem } \\
\text { experimental }\end{array}$ & $\begin{array}{c}\text { práticas de } \\
\text { ensino que } \\
\text { trabalicitamente } \\
\text { regras, } \\
\text { convenções e } \\
\text { metalinguagem }\end{array}$ & $\begin{array}{c}\text { práticas de ensino } \\
\text { crítico e de } \\
\text { contextualização }\end{array}$ & $\begin{array}{c}\text { práticas de } \\
\text { ensino que } \\
\text { relacionam teoria } \\
\text { a prática e focam } \\
\text { na transferência } \\
\text { de conhecimento } \\
\text { de um contexto } \\
\text { para o outro }\end{array}$ \\
\hline
\end{tabular}

Tabela 4 - Pedagogia dos Multiletramentos

Fonte: Adaptado de Kalantzis e Cope, 2006b, p. 234

Para os autores, essas quatro práticas são essenciais para a educação na contemporaneidade e não devem ser vistas de maneira sequencial, como dito anteriormente, mas usadas juntas e em diferentes combinações.

A Prática Situada é constituída pela imersão em práticas significativas dentro da comunidade dos aprendizes, os quais são capazes de participar em múltiplas e diferentes situações baseados em seus conhecimentos e experiências. A Prática Situada deve considerar as necessidades socioculturais e identidades de todos os aprendizes (KALANTZIS; COPE, 2006b, p. 33), propiciando duas possibilidades de significação: uma de transferir conhecimento adquirido e experienciar contextos culturais não familiares, como a identidade de outro local, uma comunidade étnica, um novo local de trabalho ou profissão; outra, de, ao experienciar essas novas significações, trazer novas perspectivas e novos conhecimentos para a sua própria comunidade (KALANTZIS; COPE, 2006b, p. 239).

A Instrução Aberta não implica a transmissão direta, repetições e memorizações de conhecimento, mas, sim, significativas intervenções por parte do professor para chamar a atenção para as importantes características dos novos 


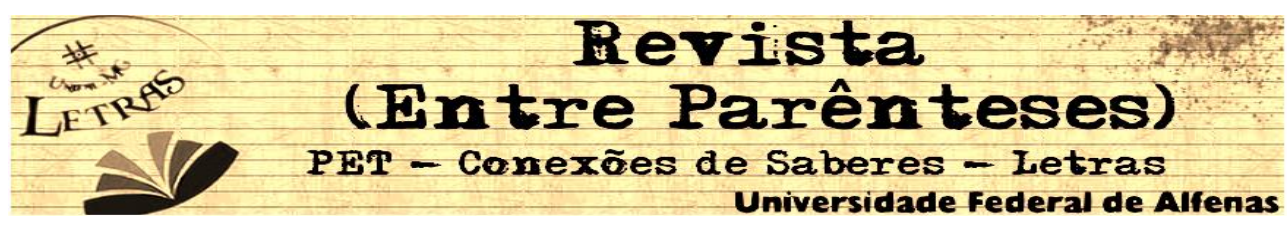

conhecimentos adquiridos pelos aprendizes em sua própria comunidade. A Instrução Aberta pressupõe o uso de metalinguagem, linguagens reflexivas e generalizações que descrevam a forma, o conteúdo e a função dos discursos e de suas práticas (KALANTZIS; COPE, 2006a, p. 33-34).

O Enquadramento Crítico tem como objetivo ajudar os aprendizes a construírem criticidade em sua prática, partindo da Prática Situada pela imersão em práticas significativas e a partir da Instrução Aberta em relação às características históricas, sociais, culturais, políticas, ideológicas e das relações sistêmicas particulares entre conhecimento e práticas sociais. Com o Enquadramento Crítico, o aprendiz constrói o distanciamento necessário sobre o que aprendeu, podendo assim criticar construtivamente, considerar a sua cultura local, estender e aplicar criativamente e, eventualmente, inovar por si mesmo dentro de velhas e novas comunidades (KALANTZIS; COPE, 2006a, p. 34).

A Prática Transformadora implica na ideia de que não é suficiente ser capaz de articular o entendimento das relações intrassistêmicas ou criticar as relações extrassistêmicas, mas que precisamos voltar ao conhecimento adquirido na comunidade, isto é, à Prática Situada, e agora repensá-la, para que a prática se torne reflexiva. Os aprendizes precisam demonstrar como eles podem redesenhar práticas aos seus objetivos e conhecimento. Devem ser capazes de mostrar que podem implementar os conhecimentos adquiridos pela Instrução Aberta e o Enquadramento Crítico em práticas que os ajudem a aplicar e a revisar o que aprenderam. 


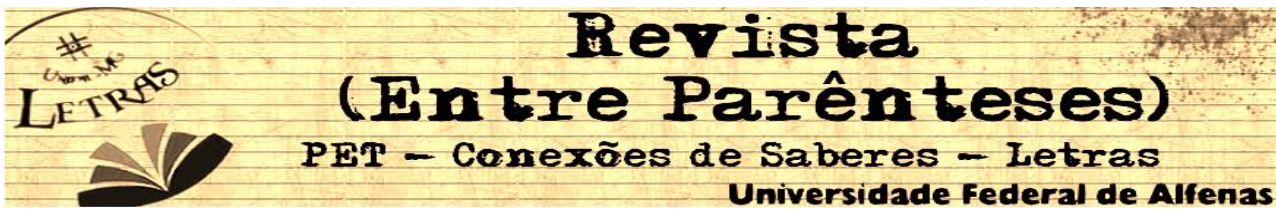

\title{
Considerações finais
}

Para tanto devemos repensar o currículo escolar para a educação do século XXI, um currículo voltado para as novas práticas de letramentos que estão interconectadas à sociedade contemporânea. Como nos mostra Lemke (2010, p. 3):

\begin{abstract}
precisamos renovar nossas velhas formas de tratar destes fenômenos. Não é mais suficiente imaginar que as sociedades são 'mentes' individuais e autônomas de algum modo dissociadas do mundo material. Não podemos continuar pensando que exista apenas um 'letramento' o que isto seja apenas o que as mentes individuais fazem quando confrontadas com um símbolo de cada vez.
\end{abstract}

Devemos sair do paradigma dos letramentos somente das culturas valorizadas ou do impresso e abrir espaço para novos letramentos advindos das tecnologias, tendo como pressuposto que "toda nova comunidade, toda comunidade transformada, potencialmente representa um novo letramento, Todo novo sistema de práticas convencionais para comunicações significativas já é um novo letramento, englobado em novas tecnologias." (ibidem)

A cada dia novos desafios são impostos pelos grandes avanços tecnológicos das TICs, nos quais nossos alunos se inserem rapidamente. Sendo assim, "todos os participantes em novas comunidades, em novas práticas sociais, potencialmente tornam disponíveis para nós novas identidades enquanto indivíduos e novas formas de humanidade enquanto membros da comunidade." (LEMKE, 2010, p. 5).

Não podemos nos desassociar dos avanços tecnológicos da sociedade contemporânea e de suas complexas práticas sociais para pensarmos a escola do futuro, que precisa estar pautada na construção de práticas significativas dentro da comunidade dos 


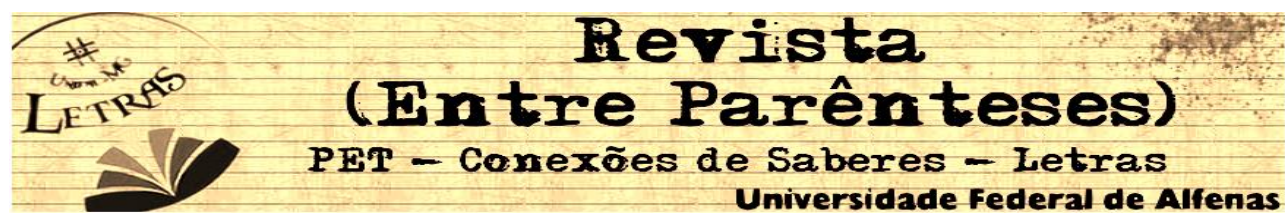

aprendizes, que corroborem com a construção de criticidade do conhecimento e que proponham a formação de um cidadão contemporâneo para os novos ambientes de estudo, trabalho, lazer, governabilidade advindos das novas práticas sociais do mundo moderno.

\section{Referências bibliográficas}

COLL, C.; MONEREO, C. Educação e aprendizagem no século XXI. In: COLL, C.; MONEREO, C (Eds). Psicologia da Educação Virtual - Aprender e ensinar com as tecnologias da informação e da comunicação. (Pp. 15-46). Porto Alegre, RS: Artmed, 2010.

KALANTZIS, M.; COPE, B. (Eds.). Multiliteracies - A Pedagogy of Multiliteracies: Designing Social Futures - The New London Group. In: COPE, B; KALANTZIS, M. (Eds.). Multiliteracies: Literacy learning and the design of social futures. New York: Routhledge, 2006[2000]. Pp. 8-36. (2006a)

KALANTZIS, M.; COPE, B. (Eds.). Pedagogy - The 'how' of Multiliteracies. In: COPE, B; KALANTZIS, M. (Eds.). Multiliteracies: Literacy learning and the design of social futures. New York: Routhledge, 2006[2000]. Pp. 198-348. (2006b)

KLEIMAN, A. B. Os significados do letramento: uma perspectiva sobre a prática social da escrita. Campinas, SP: Mercado de Letras, 1995. Coleção Letramento, Educação e Sociedade.

LANKSHEAR C.; KNOBEL M. Critical Cyberliteracies: What Young People can Teach us About Reading and Writing the World. Keynote paper presented at the National Council of English Teachers' Assembly for Research Mid-Winter Conference. New York, February 22-24, 2002.

LEMKE, J.L. Letramento Metamidiáticos: Transformando significados e mídias. Trabalhos em Linguistica Aplicada, vol.49 no2. Campinar July/Dec 2010. 


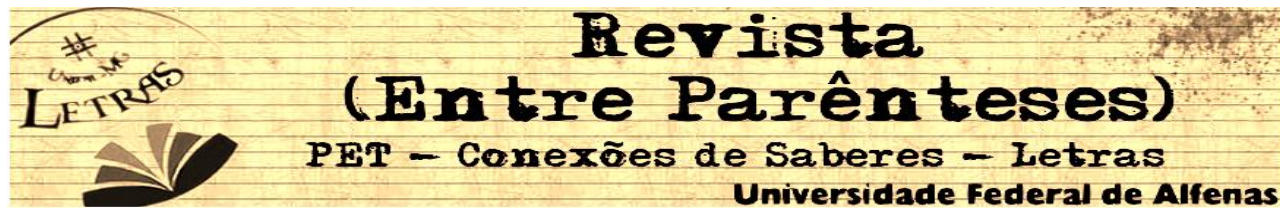

NEW LONDON GROUP, A pedagogy of multiliteracies: Designing social futures. Harvard Educational Review, 66(1), 1996.

ROJO, R. Alfabetismo(s), letramento(s), multiletramento(s): Desafios contemporâneos à Educação de Adultos. In: COSTA, R. P.; CALHAU, S. (Orgs.) E uma educação pro povo, tem? Rio de Janeiro: Ed. Caetés, 2010. Pp. 75-90

- Gêneros Discursivos do Círculo de Bakhtin e Multiletramentos. In: Escola Conectada: os multiletramentos e as TICs. São Paulo: Parábola Editorial, 2013b. pp. 13-36.

Letramentos Múltiplos, escola e inclusão Social. São Paulo: Parábola Editorial, 2009.

SHAYO, C., Olfman, L., IRIBERRI, A. \& IGBARIA, M. The Virtual Society: its driving forces, arrangements, practices and implications. In J. Grackenbach (Ed.), Psychology and the Internet (Pp. 187220). San Diego: Elsevier, 2007.

STREET, B.V. Cross-cultural Approaches to Literacy. New York: Cambridge University Press, 1993. Disponível em: http://www.amazon.com/Cross-Cultural-Approaches-LiteracyCambridge-Literate/dp/0521409640, acesso em 25/03/2011. 